\title{
Cell Therapy for Cardiovascular Disease: A Comparison of Methods of Delivery
}

\author{
Nabil Dib • Harris Khawaja • Samantha Varner • \\ Megan McCarthy $\cdot$ Ann Campbell
}

Received: 27 September 2010 / Accepted: 23 November 2010/Published online: 23 December 2010

(C) The Author(s) 2010. This article is published with open access at Springerlink.com

\begin{abstract}
The field of myocardial regeneration utilizing novel cell-based therapies, gene transfer, and growth factors may prove to play an important role in the future management of ischemic heart disease and cardiomyopathy. Phases I and II clinical trials have been published for a variety of biologics utilizing four methods of delivery: systemic infusion, intracoronary infusion, transvenous coronary sinus, and intramyocardial. This review discusses the advantages and disadvantages of the delivery approaches above.
\end{abstract}

Keywords Catheter - Intramyocardial delivery ·

Intravenous $\cdot$ Intracoronary $\cdot$ Coronary sinus

Despite advances in prevention and treatment, coronary heart disease (CHD) is still the leading cause of morbidity and mortality. More than 1.26 million Americans were diagnosed with CHD in 2006, and one million suffered myocardial infarctions (MI). Only one third of these patients experience a full recovery and over 550,000 develop congestive heart failure. The direct and indirect costs of CHD are estimated to be $\$ 177.1$ billion for 2010 [1]. Although current treatment options, such as pharmacological therapies and revascularization procedures have achieved important advances, these treatments are not always completely effective. In addition, there are currently no treatments to restore permanently damaged myocardium. The field of myocardial regeneration (angiogenesis and myogenesis) might prove to play an important role in the

\footnotetext{
N. Dib $(\bowtie) \cdot$ H. Khawaja $\cdot$ S. Varner $\cdot$ M. McCarthy $\cdot$

A. Campbell

Mercy Gilbert and Chandler Regional Medical Centers,

3555 S. Val Vista Dr.,

Gilbert, AZ 85297, USA

e-mail: ndib@heartsciencescenter.com
}

future management of patients who suffer the effects of myocardial ischemia and injury.

The delivery methods identified are used to deliver biologics such as stem cells or other therapeutic substances to the vascular system or directly into the myocardium and can be administered via different routes. The four major techniques for stem cell administration that will be addressed include (1) intramyocardial which include epicardial and transendocardial; (2) intracoronary; (3) transvenous coronary sinus; and (4) intravenous. Variations within each approach have been developed to solve issues of safety, feasibility, cell viability, and retention. The following is a summary of each anatomical approach and an analysis of the pros and cons of various methods within each of them [2].

A report published by the International Society for Cardiovascular Translational Research published recommendations for the criteria for training on these methods of delivery, Dib et al. and describes some important key elements [2].

These therapies remain in the early stages of development and implementation. As a result, significant questions persist regarding the safest and most efficacious approach. Issues of cell type, dose, distribution, retention, and method of administration for various indications have been explored extensively [3-8]. A limitation of cell therapy or other biologics for cardiac regeneration is that these substances when injected directly into the myocardium are capable of entering the vasculature and migrating to remote organs [3]. Hou et al. [3] demonstrated retention rates within the heart of $11 \%$ intramyocardial (IM), 3\% intracoronary (IC), and 3\% intravenous (IV). Significant numbers of cells are trapped in the lungs- $47 \%$ (IC), $26 \%$ (IM), 43\% (IV) - and lesser numbers travel to the liver, spleen, and kidneys. 


\section{Intramyocardial Administration}

IM administration involves injection of therapeutic agents directly into the myocardium. Injections are most frequently made into the left ventricle by a direct epicardial approach or using a catheter-based transendocardial approach.

Epicardial injection is considered the most reliable method of delivery, which also results in higher cell retention within the myocardium [2, 3, 9-11]. In previous clinical trials of epicardial injection, cell transplant was performed using a minimally invasive surgical approach via a left anterior mini-thoracotomy [12] or combined with coronary artery bypass graft or other open heart procedures [9-11]. Surgical exposure of the heart provides direct access and visualization of the epicardium. Location of the injection sites are identified prior to surgery using noninvasive methods including nuclear imaging and echocardiography. During surgery, injection sites are located by direct visualization and therapy is administered to the external surface of the heart via a standard syringe. Injections can be made into a beating or arrested heart.

Drawbacks to this procedure include its invasive nature. This procedure also limits access to certain areas of the left ventricle such as the septum. There is also a risk of perforation at the injection sites inside the left ventricle (LV), as well as systemic embolization. Tissue inflammation may also increase the risk of cardiac arrhythmias or require the use of corticosteroids or other anti-arrhythmic agents $[2,13]$.

Transendocardial injection utilizes a percutaneous catheter-based approach. There are varieties of catheters currently undergoing Phases I and II clinical trials which use either a fluoroscopic 2-dimensional (2D) guidance system or a 3-dimensional (3D) system. The Helix ${ }^{\mathrm{TM}}$ infusion catheter (BioCardia, Inc., South San Francisco, CA) and the MyoCath ${ }^{\mathrm{TM}}($ Bioheart Inc., Sunrise, FL), are 2D systems. The Myostar ${ }^{\mathrm{TM}}$ Injection Catheter is combined with a 3D guidance system NOGA ${ }^{\circledR}$ XP (Biologics Delivery Systems, Diamond Bar, CA) [4-6, 14, 15].

Unlike the surgical method, this procedure can be extended to the high-risk population and be repeated if needed. Preclinical evidence indicates that this approach achieves better myocardial cell retention when compared to intravascular infusion possibly resulting in greater therapeutic effects $[3,12]$. The 3D-guided system also avoids local toxicity by distributing the injections across the infarct area, border area of the infarct, and ischemic area. As with all forms of endocardial injection, the risk of perforation, tissue irritation, and arrhythmia still remains.

BioCardia's Helical Infusion Catheter is a catheter with a small, hollow, distal corkscrew needle, which is rotated into tissue to provide active fixation during drug delivery similar to the active fixation electrodes used in cardiac pacing [16]. This system provides a means for fixation to the beating heart wall, uses fluoroscopic imaging, crosses the aortic arch and valve over a guide wire with BioCardia's Morph $^{\circledR}$ Deflectable steerable guide, and allows $3^{\circ}$ of freedom to maximize operator control. The Morph ${ }^{\circledR}$ Deflectable Guide Catheter can be used to steer a guide wire through the aortic valve for transendocardial delivery from within the LV. For transendocardial delivery, the Morph ${ }^{\circledR}$ Deflectable Guide Catheter is advanced over the wire, and the wire is removed to allow for advancement and navigation of the Helical Infusion Catheter [4-6]. This catheter is under investigational use in multiple ongoing clinical trials $[4-6,14]$.

The MyoCath ${ }^{\mathrm{TM}}$ system utilizes a 115 -cm-long deflectable injection catheter that contains a single core 25 -gauge needle which is advanced and retracted from the tip of the catheter and provides for multiple injections to a predetermined needle insertion depth [7].

The Myostar ${ }^{\mathrm{TM}}$ is a steerable catheter equipped with a location sensor and a retractable, hollow 27-gauge needle. The catheter interfaces with the $\mathrm{NOGA}^{\circledR} 3 \mathrm{D}$ electromagnetic cardiac mapping system for local agent delivery into the myocardium [17]. The NOGA ${ }^{\circledR}$ map is a $3 \mathrm{D}$ reconstruction of the $\mathrm{LV}$ from electromechanical points obtained by the mapping catheter. The $\mathrm{NOGA}^{\circledR}$ map discriminates between areas of MI, the border zone of the MI, and normal myocardium [18]. The precise areas intended for injection can be identified when used in combination with imaging techniques such as echocardiography to measure wall thickness and single-photon emission computed tomography to assess myocardial perfusion [19]. This information provides increased accuracy and homogeneous distribution of injections $[8,15$, 17, 20-22].

\section{Intracoronary Administration}

Intracoronary administration is the preferred technique following acute myocardial infarction and has been previously described extensively [2, 23-26]. Similar to balloon angioplasty, treatments commonly performed for coronary artery occlusions, IC transfer is the most practiced technique of coronary cell transfer. Cells are injected through the delivery catheter at slow or high flow rates while maintaining coronary flow (non-occlusive) or interrupting it with balloon occlusion ("stop-flow" method) [2] In the case of non-occlusive angioplasty method, a balloon catheter or specialty catheters are used for the sub-selective injection in the coronary vessel. "Stop-flow" method uses a temporary balloon inflation to reduce cell loss due to speed of blood flow. New techniques and devices are currently being developed and tested [2]. 
Potential advantages may include homogenous distribution of the cells in the targeted myocardium and can be applied in studies for chronic myocardial ischemia or ischemic LV dysfunction [2]. This procedure requires cell migration which is partially guided by a phenomenon called stem cell homing. Cells migrate preferentially toward damaged myocardium and retention is largely dependent on adhesion to the endothelial layer of the vasculature $[2,23-27]$.

Issues to consider regarding this method include postinfusion blood flow in the target artery, timing of cell delivery, type of cell and cell preparation. Total occlusion of the coronary artery from the balloon inflation may lead to decreased blood flow which could cause ischemia leading to arrhythmia. The movement of large cells or particularly viscous suspensions may pose risk of occlusion or emboli which may also reduce accuracy of targeting and retention $[24,28]$. This method is also unsuitable when inflow arteries are occluded [12].

\section{Retrograde Coronary Sinus Delivery}

The coronary sinus (CS) and coronary veins have been utilized in applications for several therapeutic interventions. The retrograde coronary sinus delivery method provides access to the target ischemic and infarcted regions of the heart. Details of this procedure have been previously described $[2,26,29,30]$. A small number of preclinical and early clinical studies demonstrated safety and feasibility of delivering stem cells via the coronary sinus. Coronary sinus delivery is the preferred option in cases of severe subtotal stenosis of one or more coronary arteries or severe aortic stenosis. This approach provides safe and accurate access to most of the myocardium creating more homogenous delivery [2].

Potential limitations and complications of this technique include variability in coronary sinus anatomy and coronary sinus rupture. Access to CS will not be available in heart failure patients with resynchronization devices. Issues to consider regarding this method include the type of cell or cell preparation. The movement of large cells or particularly viscous suspensions may pose risk of occlusion or emboli. Also important is the effectiveness of cell homing. There is insufficient evidence to determine whether or not homing is effective with all forms of heart damage including chronic disease or remodeling as a result of previous MI [2, 26, 29, 30].

\section{Intravenous Administration}

Systemic stem cell delivery is very low risk and utilizes a standard intravenous infusion. It is the easiest to administer and the least invasive route of delivery. This delivery method depends heavily stem cell homing signals to the area of injury following an acute myocardial infarction. Preclinical studies indicate low cell retention within the heart following IV infusion and that a significant number are trapped in the lungs [31].

\section{Conclusion}

Biological therapeutics can be delivered utilizing several approaches. Intramyocardial, epicardial, and transendocardial delivery approaches are shown to be accurate and reliable. The epicardial approach provides direct visualization of the heart allowing for more accurate administration, but is high risk due to its invasive nature. Transendocardial methods that utilize the 3D mapping systems provide increased accuracy. The potential for perforating the myocardium poses the most serious risk for these approaches. The intracoronary method is preferred post-acute MI and is similar to balloon angioplasty, a commonly performed procedure. It is dependent on cell retention and additional factors such as timing of delivery, cell adhesion and homing. Coronary sinus delivery is considered lower risk and is a potentially effective method. Limitations of this procedure include the variability in coronary sinus anatomy and risk of coronary sinus rupture. Intravenous biologics delivery is the easiest and least invasive of all discussed methods, but relies heavily on cell homing.

Optimizing the safety and accuracy of these procedures by establishing training guidelines can significantly affect the outcomes of these therapies. Initial recommendations have been published for training on these methods of delivery by the Task Force for the International Society for Cardiovascular Translational Research [2].

Controversies and challenges that still remain in the field of cell-based therapies include optimal cell type, delivery route, timing, therapeutic dose, cell survival and retention. Current preclinical investigations aimed at enhancing cell survival and retention includes genetic modifications, combining stem cells with gene products or biomaterials such as collagen matrix [32]. Ongoing and future clinical studies can address these challenges through randomized, double-blind, placebo-controlled study designs [33, 34].

Open Access This article is distributed under the terms of the Creative Commons Attribution Noncommercial License which permits any noncommercial use, distribution, and reproduction in any medium, provided the original author(s) and source are credited. 


\section{References}

1. American Heart Association Heart Disease and Stroke Statistics. (2010). Update at-a-glance. Dallas: American Heart Association.

2. Dib, N., Menasche, P., Bartunek, J., et al. (2010). Recommendations for successful training on methods of delivery of biologics for cardiac regeneration: a report of the International Society for Cardiovascular Translational Research. Journal of the American College of Cardiology Cardiovascular Interventions, 3, 265-75.

3. Hou, D., Youssef, E. A., Brinton, T. J., et al. (2005). Radiolabeled cell distribution after intramyocardial, intracoronary, and interstitial retrograde coronary venous delivery: implications for current clinical trials. Circulation, 112(Suppl I), I150-I156.

4. Sherman, W., Martens, T. P., Viles-Gonzalez, J. F., \& Siminiak, T. (2006). Catheter-based delivery of cells to the heart. Nature Clinical Practice. Cardiovascular Medicine, 3(Suppl 1), S58S60.

5. Biocardia (2005) A Phase I/II, Randomized, double-blinded, placebo-controlled study of the safety and efficacy of transendocardial injection of autologous human cells (bone marrow or mesenchymal) in patients with chronic ischemic left ventricular dysfunction and heart failure secondary to myocardial infarction. http://clinicaltrials.gov/archive/NCT00102128/2005_12_08. Accessed 9 February 2010.

6. de la Fuente, L. M., Stertzer, S. H., Argentieri, J., et al. (2007). Transendocardial autologous bone marrow in chronic myocardial infarction using a helical needle catheter: 1 year follow up in an open-label, nonrandomized, single-center pilot study (the TABMMI study). American Heart Journal, 154, 79.

7. Kaider, H. K., Ye, L., \& Ashraf, M. (2008). MyoCell, a cellbased, autologous skeletal myoblast therapy for the treatment of cardiovascular diseases. Current Opinion in Molecular Therapeutics, 10(6), 611-621.

8. Fuchs, S., Dib, N., Cohen, B., et al. (2003). A randomized double blind placebo controlled multicenter pilot study of the safety and feasibility of $\mathrm{Ad}_{\mathrm{GV}}$ VEGF121.10 via an intramyocardial injection catheter in patients with advanced coronary artery disease. Journal of the American College of Cardiology, 41, 21A.

9. Menasché, P., Alfieri, O., Janssens, S., et al. (2008). The Myoblast Autologous Grafting in Ischemic Cardiomyopathy (MAGIC) trial: first randomized placebo-controlled study of myoblast transplantation. Circulation, 117, 1190-1191.

10. Dib, N., Michler, R., Pagani, F., et al. (2005). Safety and feasibility of autologous myoblast transplantation in patients with ischemic cardiomyopathy: four-year follow-up. Circulation, 112, 1748-1755.

11. Pompilio, G., Steinhoff, G., Liebold, A., Pesce, M., Alamanni, F., Capogrossi, M. C., et al. (2008). Direct minimally invasive intramyocardial injections of bone marrow-derived AC133+ stem cells in patients with refractory ischemia: preliminary results. Thoracic and Cardiovascular Surgeon, 56(2), 71-76.

12. Perin, E. C., Silva, G. V., Assad, J. A., Vela, D., Buja, L. M., Sousa, A. L., et al. (2008). Comparison of intracornary and transendocardial delivery of allogeneic mesenchymal cells in a canine model of acute myocardial infarction. Journal of Molecular and Cellular Cardiology, 44(3), 46-495.

13. Cheng, Y., Sherman, W., Yi, G., Conditt, G., Sheehy, A., Martens, T., et al. (2009). Real time 3D echo guided intramyocardial delvery of mesenchymal precursor cells in a chronic myocardial infarct ovine model using a novel catheter. Journal of the American College of Cardiology, 53(10 Suppl A), A41.

14. Amado, L. C., Saliaris, A. P., Schuleri, K. H., et al. (2005). Cardiac repair with intramyocardial injection of allogeneic mesenchymal stem cells after myocardial infarction. PNAS, 102, 11474-11479.
15. Vale, P. R., Losordo, D. W., Milliken, C. D., et al. (2001). Randomized, single-blind, placebo-controlled pilot study of catheter-based myocardial gene transfer for therapeutic angiogenesis using left ventricular electromechanical mapping in patients with chronic myocardial ischemia. Circulation, 103, 2138-2143.

16. Dib, N., Taylor, D. A., \& Diethrich, E. B. (Eds.). (2006). Stem cell therapy and tissue engineering for cardiovascular repair: from basic research to clinical applications, 1st edition (pp. 213-230). New York: Springer.

17. Fuchs, S., Satler, L. F., Kornowski, R., et al. (2003). Catheterbased autologous bone marrow myocardial injection in nooption patients with advanced coronary artery disease: a feasibility study. Journal of the American College of Cardiology, 41, 1721-1724.

18. Kornowski, R., Leon, M. B., Fuchs, S., Vodotz, Y., Flynn, M. A., Gordon, D. A., et al. (2000). Electromagnetic guidance fir catheter-based transendocardial injection: a platform for intramyocardial angiogenesis therapy. Results in normal and ischemic porcine models. Journal of the American College of Cardiology, 35(4), 1031-1039.

19. Smits, P. C., van Geuns, E. J., Poldermans, D., Bountioukos, M., Onderwater, E. E., Lee, C. H., et al. (2003). Catheter-based intramyocardial injection of autologous skeletal myoblasts as a primary treatment of ischemic heart failures: clinical experience with six month follow-up. Journal of the American College of Cardiology, 42(12), 2063-2069.

20. Vale, P. R., Losordo, D. W., Tkebuchava, T., Chen, D., Milliken, C. E., \& Isner, J. M. (1999). Catheter-based myocardial gene transfer utilizing nonfluoroscopic electromechanical left ventricular mapping. Journal of the American College of Cardiology, 34, 247-250.

21. Dib, N., Campbell, A., Jacoby, D. B., et al. (2006). Safety and feasibility of percutaneous autologous skeletal myoblast transplantation in the coil-infarcted swine myocardium. Journal of Pharmacological and Toxicological Methods, 54(1), 71-77.

22. Dib, N., Diethrich, E. B., Campbell, A., et al. (2002). Endoventricular transplantation of allogenic skeletal myoblasts in a porcine model of myocardial infarction. Journal of Endovascular Therapy, 9, 313-319.

23. Bolukoglu, H., Liedtke, A. J., Nellis, S. H., Eggleston, A. M., Subramanian, R., \& Renstrom, M. (1992). An animal model of chronic coronary stenosis resulting in hibernating myocardium. The American Journal of Physiology, 263, H20-H29.

24. Bartunek, J., Wijns, W., Heydnrickx, G. R., \& Vanderheyden, M. (2006). Timing of intracoronary bone-marrow-derived stem cell transplantation after ST-elevation myocardial infarction. Nature Clinical Practice. Cardiovascular Medicine, 3(Suppl 1), 552-556.

25. Liano, R., Epstein, S., Zhou, R., et al. (2008). Intracoronary delivery of mesenchymal stem cells at high flow rates after myocardial infarction improves distal coronary blood flow and decreases mortality in pigs. Catheterization and Cardiovascular Interventions, 73, 251.

26. Pohl, T., Giehrl, W., Reichart, B., et al. (2004). Retroinfusionsupported stenting in high-risk patients for percutaneous intervention and bypass surgery: results of the prospective randomized myoprotect I study. Catheterization and Cardiovascular Interventions, 62, 323-330.

27. Boekstegers, P., Giehrl, W., von Degenfeld, G., \& Steinbeck, G. (1998). Selective suction and pressure-regulated retroinfusion: an effective and safe approach to retrograde protection against myocardial ischemia in patients undergoing normal and high risk percutaneous transluminal coronary angioplasty. Journal of the American College or Cardiology, 31, 1525-1533.

28. Vanderheyden, M., Vercauteren, S., Mansour, S., et al. (2007). Time-dependent effects on coronary remodeling and epicardial conductance after intracoronary injection of enriched hematopoietic 
bone marrow stem cells in patients with previous myocardial infarction. Cell Transplantation, 16, 919-925.

29. Raake, P., von Degenfeld, G., Hinkel, R., et al. (2004). Myocardial gene transfer by selective pressure-regulated retroinfusion of coronary veins: comparison with surgical and percutaneous intramyocardial gene delivery. Journal of the American College of Cardiology, 44, 1124-1129.

30. von Degenfeld, G., Raake, P., Kupatt, C., et al. (2003). Selective pressure-regulated retroinfusion of fibroblast growth factor-2 into the coronary vein enhances regional myocardial blood flow and function in pigs with chronic myocardial ischemia. Journal of the American College of Cardiology, 42, 1120-1128.

31. Barbash, I. M., Chouraqui, P., Baron, J., et al. (2003). Systemic delivery of bone marrow-derived mesenchymal stem cells to the infarcted myocardium: feasibility, cell migration, and body distribution. Circulation, 108, 863-868.

32. Dai, W., Hale, S. L., Kay, G. L., Jyrala, A. J., Kloner, R. A., \& Robert, A. (2009). Delivering stem cells to the heart in a collagen matrix reduces relocation of cells to other organs as assessed by nanoparticle technology. Regenerative Medicine, 4, 387-395.

33. Bartunek, J., Sherman, W., Vanderheyden, M., Fernandez-Aviles, F., Wijns, W., \& Terzic, A. (2009). Delivery of biologics in cardiovascular regenerative medicine. Clinical Pharmacology and Therapeutics, 85(5), 548-52.

34. Gersh, B. J., Simari, R. D., Behfar, A., Terzic, C. M., \& Terzic, A. (2009). Cardiac cell repair therarpy: a clinical perspective. Mayo Clinic Proceedings, 84, 876-892. 